\title{
Polarización espacial y dependencia en los países del Plata
}

\author{
ANTONIO Zárate MARTíN*
}

\section{LA VARIEDAD DEL MODELO REGIONAL}

Los países del Plata se extienden sobre una enorme superficie de $3.374 .777 \mathrm{kms}^{2}$ del hemisferio sur, a más de $10.000 \mathrm{~km}$ de distancia de los principales centros de decisión política y económica del planeta; constituyen un espacio de contrastes, compuesto por sistemas orográficos andinos, escudos cristalinos y una enorme llanura de acumulación, por climas variados que resultan del choque de masas de aire tropical y polares en un territorio que se alarga en sentido norte sur desde más allá del Trópico de Capricornio, al norte del paralelo 20, al cabo de San Pio, en el extremo meridional de la isla grande de Tierra de Fuego; por dominios vegetales que van desde la selva subtropical al dominio antártico.

En ese enorme espacio, Paraguay se esfuerza por salir del subdesarrollo, y Argentina y Uruguay por integrarse en el contexto de los paises evolucionados, recuperando cotas de bienestar alcanzadas en el pasado y perdidas en la actualidad. Sin embargo, para ello es preciso vencer obstáculos y dificultades que derivan del carácter periférico de estas tierras y de los aspectos estructurales de una crisis generada por los mecanismos de dependencia dentro del funcionamiento del capitalismo periférico, agravada por la actual crisis financiera del Tercer Mundo.

La mayor parte de la superficie, $2.779 .221 \mathrm{~km}^{2}$, el $83 \%$, corresponde a Argentina, incluyendo su espacio continental y Tierra del Fuego. Este pais, con una longitud de $3.690 \mathrm{~km}$ de norte a sur, una anchura máxima

* Departamento de Geografía. UNED. 
de $1.423 \mathrm{~km}$ y mínima de $399 \mathrm{~km}$, en sentido este oeste, y con recursos naturales a la medida de su tamaño, es uno de los gigantes del planeta. Es el segundo país de Sudamerica por su extensión, cinco veces mạ́s grande que España. Sin embargo, su población, 31.497 .000 millones en 1987 , es escasa y se encuentra excesivamente concentrada.

Por el contrario, Uruguay, en la ribera oriental de los ríos de la Plata y Uruguay, es el Estado más pequeño de América del Sur después de Surinam, con $176.215 \mathrm{~km}^{2}$, y es uno de los menos poblados, con 3.012.000 habitantes en 1985 y una densidad de 17 habitantes por $\mathrm{km}^{2}$. Hasta los años 80 , era uno de los paises más prosperos de América Latina, con una relativa estabilidad política y económica con relación a sus vecinos, importantes logros sociales conseguidos en la época dorada de las exportaciones agroganaderas y de las grandes inmigraciones y un nivel de vida que le valió el calificativo de "Suiza del continente Suramericano". Sin embargo hoy se encuentra inmerso en una profunda crisis cuyas principales manifestaciones son una balanza de pagos cada vez más deficitaria, una deuda exterior de casi 3.000 millones de dolares, un fuerte paro, el aumento de la inflación con el consiguiente descenso del poder adquisitivo, en torno al $200 \%$ en los últimos diez años.

Por su parte, Paraguay, con una superficie de $406.752 \mathrm{~km}^{2}$, tres veces más grande que Uruguay, y una población de 3.922.000 habitantes en 1987, se diferencia de los anteriores Estados por el dominio absoluto del clima y la vegetación tropical, por su carácter exclusivamente interior, solo comunicado con el mar por los ríos Paraguay y Paraná, por los componentes mestizo e indigena predominantes en su población y cultura, y por un desarrollo economico y social inferior. No obstante, al igual que los otros paises del Plata su situación económica es especialmente difícil en la actualidad debido al aumento de su endeudamiento con el exterior, al incremento del paro y la inflación y a los perjuicios derivados de los programas de austeridad de sus grandes vecinos, Brasil y Argentina, que se han materilizado en la disminución de las relaciones comerciales y en la paralización de la construcción de la presa gigante de Yacerita que se había iniciado en colaboración con Argentina, siguiendo planes de aprovechamiento hidraúlico del Paraná que contaban con el precedente de la presa de Itaipu, en las inmediaciones de Ciudad del Este.

Hoy, la población, las actividades productivas, las ciudades, el poder político y financiero se hallan excesivamente concentrados en torno al estuario del Plata, donde el Gran Buenos Aires y el área urbana que forman Montevideo y los núcleos próximos de los departamentos de CoIonia, San José, Canalones y Montevideo dan origen a una megalópolis 
de 20 millones de habitantes sobre unos $300.000 \mathrm{~km}^{2}$. Todo ello dificulta la integración espacial y sectorial y obstaculiza el desarrollo económico hasta el punto de ser uno de los principales inconvenientes para la modernización del conjunto regional. Mientras las áreas metropolitanas sufren problemas derivados de deseconomías de escala, con fenómenos de saturación, congestión y deterioro medio ambiental, que hacen poco rentables los servicios y dificultan el acceso a los servicios básicos, abundan las áreas subutilizadas y los vacios intermedios, con importantes diferencias en calidad de vida y oportunidades para la población.

Esta organización del territorio es el resultado de unas formas y procesos de ocupación del espacio, heredadas del pasado, que se vinculan a la presión demográfica del exterior, representada por las grandes migraciones transoceanicas, y a formas de dependencia variadas, dentro de distintos momentos y de los mecanismos de expropiación-apropiación del excedente económico por el modo de producción capitalista. A ello se añaden la influencia del medio físico (barreras montañosas, casos de extrema áridez, regiones excesivamente frías, másas de bosque húmedo frente a áreas desérticas, desigualdad en la distribución espacial de los recursos hídricos), y las posibilidades de aprovechamiento de los recursos naturales en función de una capacidad tecnológica que varia a través del tiempo.

\section{LA PRIMERA DEPENDENCIA. EL MODO COLONIAL}

En los bordes del Imperio español, con una actividad agricola e industrial autosuficiente y un comercio internacional limitado a un papel marginal en la economía minera del Perú y a la exportación de cueros y productos subtropicales, los inicios de la colonización supusieron la primera incorporación de estos territorios al esquema de producción capitalista, dentro de la típica estructura metrópoli-satélite. En ese contexto, apoyándose en la fundación de ciudades como instrumento de control y de organización del espacio, surgieron, desde direcciones distintas, los tres primeros focos de poblamiento blanco y de explotación económica a partir de los cuales se estructuran y vertebran los paises del Plata:

Desde el alto Perú y en dirección sureste, buscando la creación de una ruta que permitiera asegurar su comunicación con España a través de una salida al Atlántico y apoyar los establecimientos mineros del altiplano andino, se fundan en el siglo XVI varias ciudades: San Miguel de 
Tucumán (1565), Córdoba del Tucumán (1573), Salta (1582), Todos los Santos de la Nueva Rioja (1591) y San Salvador de Jujuy (1593). Estas ciudades se localizan en el Noroeste, al borde de la puna y de las sierras subandinas, en tierras habitadas por indios omaguacas y diaguitas, que se hallaban sometidos a los incas desde el último tercio del siglo XV.

A partir de Chile, según directrices de su gobernador Pedro de Valdivia, se crearon en el borde oriental de los Andes áridos las ciudades de Santiago del Estero (1533), Mendoza (1561) y San Juan (1562), entre otras que no se consolidaron y desaparecieron. Con ellas, se pretendía mejorar las comunicaciones por tierra con el Alto Perú y encontrar nuevas reservas de indios. La necesidad de comunicación con el Plata y con el Paraguay, a través de Santa Fé y Corrientes, determinó la fundación de San Luis.

El primer contacto con el embudo del Plata se produjo directamente desde España, de forma casual, en 1516, cuando Juan Díaz de Solís se internó por el río de la Plata en busca de un paso entre el Atlántico y el Pacífico. En 1527, Sebastián Caboto estableció el fuerte de Sancti Spiritus, primer asentamiento de corta existencia, y en 1536, el adelantado Pedro de Mendoza construyó el fuerte de Santa María de los Buenos Aires, muy cerca de la ciudad actual con el fin de crear un punto de apoyo en al ruta hacia el alto Perú. Fracasado también este establecimiento por la naturaleza hostil y por el asedio de los indios, los españoles lo abandonaron; hubo que esperar a 1580 para que Juan de Garay llevara a cabo la definitiva fundación de Santa María de Buenos Aires, con una expedición procedente del interior.

Siguiendo esta misma dirección, Diego Matínez de Iralá fundó Asunción, a orillas del Paraguay, contando para ello con la expedición que poco antes había tenido que abandonar el fuerte de Santa María de los Buenos Aires, y desde aquí, en 1537, Santa Fe. Años más tarde, en 1588 se procedió a la fundación de San Juan de Vera de las Siete Corrientes. Desde estas tierras, con abundante población indígena, se esperaba poder exportar pieles de ganado y participar en el comercio de la plata que debería fluir desde Potosí hacia el Atlántico.

La proximidad de las colonias portuguesas y el peligro que representaba el expansionismo de sus colonos, ya en el siglo xVIII, motivó la fundación por parte de las autoridades españolas de las ciudades de Colonia y de Montevideo (1724), en la orilla izquierda del río de la Plata.

En torno a todos estos asentamientos aparecieron formas de organización espacial que perduraron hasta mediados del siglo XIX, y se desa- 
rrollaron economías regionales de limitado alcance cuyo objetivo prioritario era la subsistencia, si bien existió cierto grado de especialización que permitió el comercio entre ellas, en base a razones de complementaridad, y un pequeño comercio de exportación hacia áreas más lejanas.

La Pampa inició entonces la marcha hacia su especialización ganadera, gracias a la rapidez de reproducción de los animales llevados por los conquistadores en un medio excepcionalmente favorable. Las formas de explotación consistieron en las "vaquerías", matanza de rebaños de animales sin dueños, de los que se aprovechaba sólo el sebo y el cuero, objeto de comercio o contrabando con Brasil, y en las "estancias", enormes fincas que se convertirian en la base fundamental de la economía argentina. Su origen se encuentra en las concesiones de tierras hechas a los conquistadores cuando se fundaban las ciudades.

Mendoza, con la vid, introducida por los jesuitas en el XVI con cepas traídas de Chile y Perú; Tucumán, con la caña de azucar, también introducida por los jesuitas en el siglo XVII, y algunos oasis del Noroeste, con cultivos de algodón, tabaco, frutales y vid, se configuraron como tempranos focos de cultivos industriales que perduran hasta nuestros días.

Además de la actividad artesanal doméstica, algunas localidades desarrollaron cierta especialización industrial: Tucumán fabricaba carros, algodón y paños de lana; Mendoza, carros, vinos y frutos secos; Paraguay y Misiones, azúcar, hierba mate y telas de algodón; Corrientes construía barcos.

\section{EL MODELO DE TRANSICIÓN}

Las reformas de los Borbones, que culminan con la creación del Virreinato del río de la Plata en 1776 y las regulaciones de libre comercio en 1777 y 1778 , la proximidad de las colonias portuguesas, el desarrollo de Buenos Aires y Montevideo, como puertos de salida de la plata del Perú y de relación con España, iniciaron a finales del siglo xvIII un proceso de reorientación económica, redistribución de la población y reorganización espacial del territorio en beneficio del litoral. La posterior independencia, con la creación de fronteras entre los nuevos Estados, el establecimiento de tarifas arancelarias interprovinciales dentro de Argentina y la libertad de comercio, impulsaron aún más el desarrollo del litoral y aumentaron el aislamiento de un interior, provocado además, de forma natural, por la distancia y las dificultades de comunicación. 


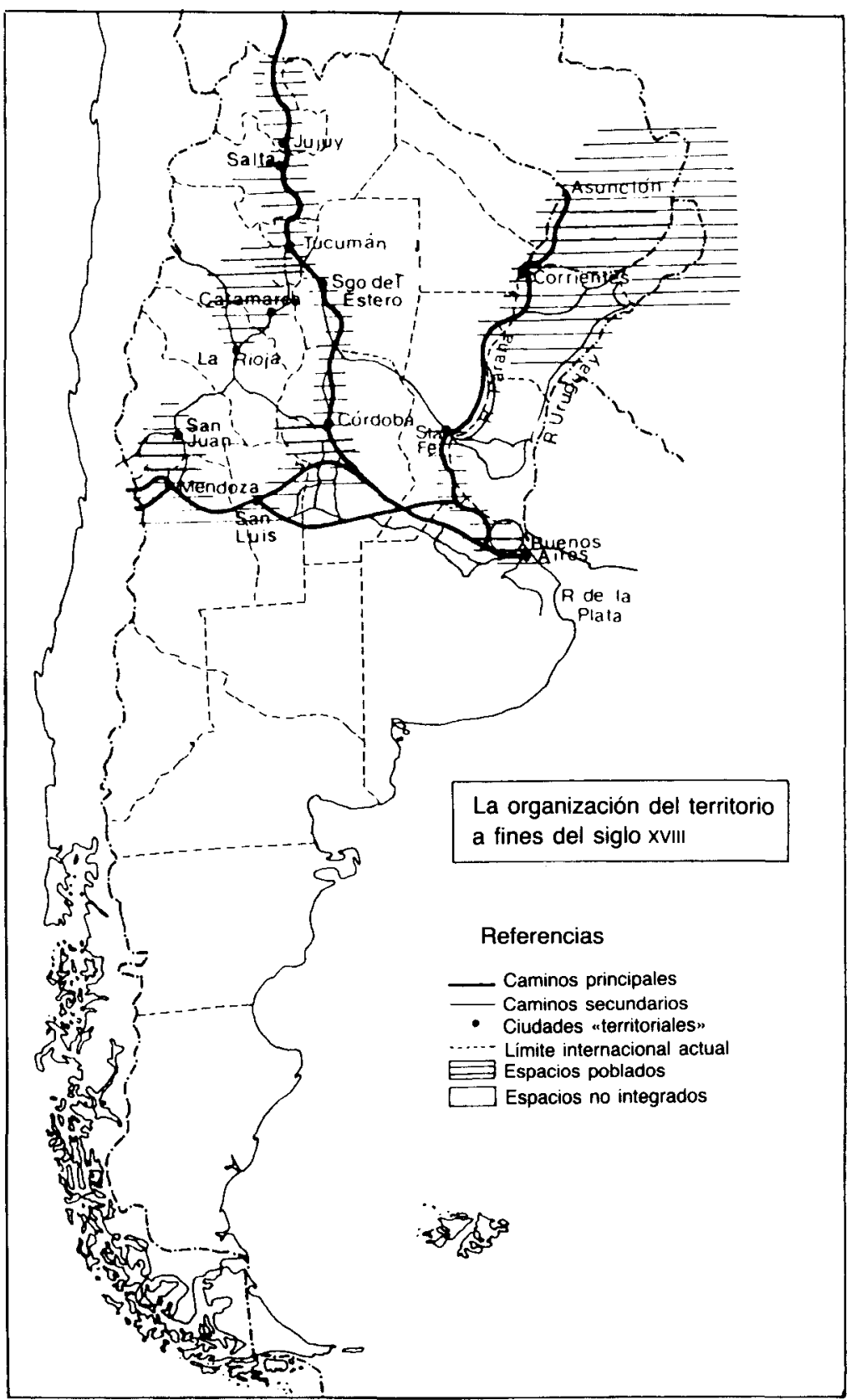

Fig. 1. Tomado y modificado de L. Bortagaray (1988) 
A lo largo de este período, los habitantes de la Argentina "civilizada" crecieron considerablemente, de 269.000 en 1780 a 1.107 .000 en 1855, y las poblaciones del interior y el litoral se equilibraron. Mientras Buenos Aires elevó su participación en el conjunto de la población total del país en 1855 , con $1 / 4$ de los efectivos demográficos, el Noroeste y Mesopotamia empezaron a ver declinar su porcentaje de participación poblacional. Por su parte, Uruguay dobló su población entre 1828 y 1852, alcanzando 132.000 habitantes en la última fecha, debido en gran parte a la inmigración procedente del sur de Europa.

Por entonces, sin que todavía el comercio internacional estuviera en una etapa de gran dinamismo, se inició la consolidación de estructuras primarias productivas orientadas a la exportación y se crearon las condiciones objetivas para el primer desarrollo económico de los países del Plata, basado en el modelo de crecimiento hacia afuera que empezó a triunfar hacia 1880.

Paulatinamente, a través del libre comercio con Gran Bretaña y del desarrollo de la ganadería, sobre el binomio complementario ganaderíasaladero, la Pampa se fue integrando en un comercio y mercado mundial. Todo ello fue favorecido por el aumento de la demanda de carne salada para las plantaciones tropicales, la abundancia de sal de Patagonia y el aumento del ganado. En los alrededores de las ciudades de Buenos Aires, Entre Ríos y Montevideo, proliferaron los saladeros, a la vez que se inició la especialización y selección del ganado lanar, con importaciones de merinos y razas inglesas.

Por el contrario, la libertad de importación, el aislamiento y la distancia perjudicaron a Paraguay y al interior de Argentina. Privados estos territorios de la recepción de nuevas tecnologias, y dedicada la mayor parte de su población a ocupaciones de subsistencia, su agricultura y actividad industrial no pudieron competir en el mercado con el precio, calidad y variedad de los productos que llegaban de fuera.

Entre el litoral y el interior quedaba un inmenso vacio territorial, sometido al control de indios nómadas que vivian de la caza de guanacos y rheas. De Rosario a Córdoba no habia nada más que fuertes militares encargados de vigilar y proteger la ruta de los ataques de los indios.

\section{EL MODELO AGROEXPORTADOR DE DEPENDENCIA}

La demanda masiva de materias primas por parte de la Europa industrializada, sobre todo de Gran Bretaña, y la mejora de los transportes 
marítimos impulsaron la plena integración de Argentina y Uruguay en la economía mundial a través del esquema centro-periferia, coincidiendo con las grandes corrientes migratorias transoceánicas. Los países del Plata se configuran en la segunda mitad del siglo pasado como economías periféricas agroexportadoras respecto a un centro que hasta los años 30 estuvo constituido por Inglaterra. De ese centro procedieron durante mucho tiempo abundantes capitales, bienes elaborados y gran parte de los servicios.

Durante el período comprendido entre mediados del siglo $\mathrm{xIX}$ y los años 30 de nuestro siglo, Argentina y Uruguay desarrollaron una importante estructura agroportuaria, centrada en torno a Buenos Aires y Montevideo, a partir de la espectacular expansión de la producción agraria y ganadera de la Pampa y del estuario del Plata. Al mismo tiempo, la existencia de una balanza comercial favorable dio a estos paises una imagen mundial de naciones ricas y de inmigración. Por su parte, la afluencia masiva de capitales extranjeros, la revolución agrícola y la eclosición de una primera e incompleta industrialización, transformaron en profundidad a Argentina y Uruguay. Todo ello sirvió de motor para completar la ocupación efectiva del territorio, con la eliminación del peligro indio y la creación de nuevos asentamientos que ahora se vinculan a un proceso sistemático de colonización de nuevos espacios y de afirmación de grandes conjuntos regionales.

Mientras la autocapitalización de los productos agrarios de la Pampa hizo posible la revolución agricola, las inversiones de capital extranjero directamente o de forma indirecta a través del sistema bancario-financiero, facilitaron el trazado de redes ferroviarias de disposición radial a partir de Buenos Aires, Rosario y Montevideo, la construcción y el acondicionamiento de puertos para dar mayor dinamismo y eficacia a los sectores exportadores, y la realización de infraestructuras para atender el crecimiento urbano y poblacional. Con ello, este modelo de desarrollo económico, basado en la expansión del comercio internacional y el incremento del flujo de capitales, consolidó el poder de las élites rurales y originó el nacimiento de unas clases medias urbanas, practicamente inexistentes en la mayoría de los países de Latinoamérica.

La ganadería adquirió un carácter tipicamente especulativo y pasó a ocupar un primer puesto mundial por la calidad y cantidad de los rebaños. Los principales factores de progreso fueron: el aumento de la demanda; el espíritu emprendedor de ganaderos que promovieron la importación de razas selectas; la exportación de lana, en aumento hasta 1885 en Argentina y 1916 en Uruguay; la exportacion de ganado en vivo hacia los países limítrofes e Inglaterra, en este caso hasta el cierre de sus 
puertos en 1900 a este tipo de importación para evitar el contagio de una epizootia propagada desde Francia; y las innovaciones tecnológicas en el tratamiento y transporte de la carne. Hacia 1907, la carne congelada había reemplazado a los restantes productos cárnicos en las exportaciones y Argentina era el mayor proveedor de carne congelada de Gran Bretaña.

La fabricación de extractos de carne, desde 1865, y la introducción de frigoríficos en el estuario del Plata, en los alrededores de Santa Fe, Buenos Aires, La Plata y Motevideo, desde 1883, favorecieron la importación de vacunos selectos, de raza Shorthorn, Hereford y Aberdeen Angus; promovieron la transformación del paisaje de la Pampa e introdujeron nuevas formas de explotación y de distribución espacial del aprovechamiento agrícola-ganadero. Los cultivos y los sistemas ganaderos adoptaron una disposición en zonas concéntricas, de mayor a menor intensidad, a partir de un máximo junto a los frigoríicos, que recuerda al modelo de distribución de usos agrícolas de Von Thünen.

Las estancias fueron cercadas y su interior dividido con alambradas para facilitar la manipulación y la cría del ganado; se introdujeron molinos para obtener agua de las capas subterráneas y poder disponer de bebederos en los potreros, evitando los largos desplazamientos del ganado para abrevar; además, se prestó atención a la mejora de la calidad de los pastos mediante el desarrollo del cultivo de plantas forrajeras.

La ganadería lanar, que había aumentado hasta los años 80 en la Pampa, fue desplazada hacia la Patagonia; en Entre Ríos, fábricas de cecina aprovechaban la carne de rebaños vacunos menos selectos del Chaco y Corrientes; los saladeros fueron desplazados al alto Uruguay y Paraguay, con ganados apenas mejorados y razas criollas; y la fabricación de extractos de carne se replegó a lugares de Paraguay y al Mato Grosso, donde no existía otra posibilidad de aprovechamiento ganadero.

No obstante, la definitiva conquista del desierto (1879), el tendido del ferrocarril y el aporte masivo de inmigrantes modificaron la vocación exclusivamente pastoril de la Pampa hasta entonces e hicieron de Argentina, en menos de 50 años, uno de los principales graneros del mundo. La expansión de las tierras dedicadas a la producción de trigo, por otra parte el principal cultivo desde los tiempos de la colonización española, permitió eliminar a partir de 1875 las importaciones que se hacian para cubrir las necesidades de la población, inicialmente desde Chile y luego desde Estados Unidos y Australia. Pero además, pronto empezaron las exportaciones de trigo, que desde 1904 raramente se sitúan por debajo de los 2 millones de Tn, a pesar de que la llegada masiva de italianos supuso un aumento considerable del consumo nacional de este cereal, 
exactamente en una cantidad que se estima análoga a la de exportación, al modificar la dieta alimenticia de los argentinos. Por otro lado, el maíz se convirtió en el segundo cereal en importancia y sus volúmenes de exportación fueron análogos a los del trigo desde 1900, hasta el punto de hacer de Argentina un verdadero líder mundial de esta producción. Por último, hay que señalar el considerable incremento del lino por los mismos años, debido a su cultivo asociado con la alfalfa.

Esta fuerte expansión de los cereales, 13 de los 22 millones de hectáreas cultivadas en 1914, va unida a relaciones de complementariedad entre producción agrícola y ganadera. Los propietarios ganaderos imponían a los campesinos arrendatarios a corto plazo la obligación de practicar estos cultivos, y al cabo del contrato el deber de devolver las tierras sembradas de alfalfa para engorde del ganado con destino a los frigoríficos. Sin embargo, a pesar de esta relación de dependencia de la agricultura respecto a la ganadería, los cultivos acabaron dominando la economía de exportación, pasando de un $1 \%$ en el valor de las exportaciones en 1870 a un máximo del $53 \%$ en 1910.

Los tradicionales cultivos de vid y caña de azúcar de Cuyo y Tucumán también experimentaron ahora una importante expansión. Estos cultivos fueron favorecidos por la llegada del ferrocarril, la afluencia de inmigrantes italianos y españoles, la presión local sobre el gobierno de la nación para conseguir tarifas proteccionistas y el desarrollo de la Pampa como mercado consumidor. Simultáneamente, el cultivo del algodón se extendió desde $300 \mathrm{Ha}$ a más de 100.000 en 1925, favorecido por la colonización del Chaco y el aumento de precios de este producto en los mercados internacionales; en pocos años Argentina llegó a ser el sexto productor mundial de algodón. Por el contrario, la producción de granos de los pequeños oasis, en los valles de las Sierras Pampeanas, no encontraron salida y la región permaneció inmersa en una economía de subsistencia que llega hasta hoy.

En Uruguay, no se dio la misma estrecha relación agricultura-ganaderia, al no necesitarse pastos artificiales para la alimentación del ganado por la mayor abundancia de lluvias. Con un campesinado más estable por la renovación sistemática de los contratos de arrendamiento cada cuatro años, los cultivos adquirieron un desarrollo progresivo cerca del río de la Plata, sobre todo el del trigo, para abastecimiento del mercado doméstico, y el del lino, que llegó a ocupar un tercer puesto en las exportaciones, detrás de la carne y la lana.

A su vez, el comercio exterior y el crecimiento poblacional originaron una primera, escasa e insuficiente industrialización de los países del Pla- 
ta, a base de industrias derivadas de productos agropecuarios, como los frigoríficos, y de bienes de consumo interno, que se localizaron en el frente fluvial. La guerra de 1914 y el establecimiento posterior de tarifas proteccionistas para ciertas producciones favorecieron su crecimiento. En 1913 , el $71 \%$ de las manufacturas consumidas en Argentina eran fabricadas en el país, pero en su mayor parte, correspondian a industrias de alimentación, vestido e imprenta.

Todo ese proceso de puesta en explotación del territorio de los países del Plata fue acompañado de la ocupación y colonización de tierras nuevas. Se completa, así, la organización de paisajes y grandes conjuntos regionales que perduran hasta hoy, con simples modificaciones debidas al crecimiento demográfico, a las mejoras técnicas y a los altibajos socioeconómicos.

Desde mediados del siglo pasado a la primera década del nuestro, se completa la ocupación de la Pampa. Desde 1865, la promulgación de leyes provinciales de colonización, la llegada del ferrocarril, la expulsión de los indios y la intervención de compañías de colonización, como la Compañía Central de Suelo Argentino y la Compañía Central Argentina de ferrocarriles, impulsaron la creación de asentamientos y el establecimiento de colonos al oeste del Paraná, por Santa Fe, Córdoba y Entre Ríos. En cambio, la ocupación del sur solo pudo llevarse a cabo tras la guerra de exterminio indígena que fue la conquista del desierto (18791883). Entregadas las tierras en su mayor parte a los soldados en recompensa por los servicios prestados, pronto pasaron a manos de especuladores, ganaderos y compañías que concentraron la propiedad en pocas manos. La colonización fue impulsada en gran medida por compañías de colonización dependientes de los ferrocarriles, y favorecida por el propio gobierno a través de la legislación de 1876, que compartimentaba las tierras nuevas en secciones de $400 \mathrm{~km}^{2}$, divisibles a su vez en 400 lotes de $100 \mathrm{Ha}$ cada uno, de los que cuatro centrales se reservaban para crear una ciudad.

Entre 1883, recién concluida la conquista del desierto, y 1930, tuvo lugar la ocupación efectiva y la puesta en explotación de la Patagonia. En los márgenes norte, la fertilidad y la mayor accesibilidad, favorecida por la llegada del ferrocarril en 1899, propiciaron la colonización intensiva del valle del río Negro, cerca de la confluencia del Limay y el Neuquen. En cambio, al sur, la ocupación solo adquirió viabilidad económica con el desarrollo de la ganadería lanar en régimen muy extensivo, impulsada por el declive de la producción de lana en la Pampa, con el descubrimiento de petróleo en Comodoro Rivadavia en 1907, y con el apoyo oficial del gobierno a la colonización, consciente de la urgencia de ocupar 
eficazmente el territorio ante la presión reivindicativa de parte de estas tierras por Chile y el peligro de que se instalaran en ellas colonos procedentes de la vecina República. Hacia 1930, toda la Patagonia, desde el río Negro a la Tierra del Fuego, estaba repartida entre criadores de ganado lanar, aunque con una densidad de ocupación muy baja. Todavia hoy su población es escasa, poco más de un millón de habitantes, y sigue siendo un espacio pionero.

La colonización de la llanura del Chaco, en el otro extremo de Argentina, avanzó rápidamente a partir de principios de siglo. La ocupación del territorio fue vinculada a las exportaciones de madera de quebracho, a la instalación de empresas extranjeras dedicadas a la fabricación de tanino y al desarrollo de plantaciones de algodón en los abras o claros del bosque, por los altos precios alcanzados por este producto. Todo ello fue apoyado directamente por el gobierno y favorecido por la llegada del ferrocarril. La afluencia de colonos desde Paraguay y de inmigrantes de ultramar, entre ellos germanos y eslavos, hizo aumentar rápidamente su población, desde 46.000 habitantes en 1914 a 335.000 en 1937.

En Mesopotamia, entre los ríos Paraná y Paraguay, la colonización fue vinculada al aprovechamiento forestal del bosque a lo largo de la franja este del Paraná, al ferrocarril Buenos Aires-Posada, inaugurado en 1912, y al aumento de la demanda mundial de productos subtropicales tras la Primera Guerra Mundial. Con la afluencia masiva de inmigrantes después de 1920, muchos de lengua alemana, se desarrolló una agricultura intensiva de plantación, con cultivos de hierba mate, tung, té y arroz. La población pasó de 33.000 habitantes en 1895 a unos 246.000 en 1947.

Por su parte, la colonización de las tierras interiores de Uruguay se efectuó predominantemente de forma privada, ante la escasez de tierras públicas, coincidiendo con la afluencia masiva de inmigrantes europeos y la creciente estabilidad política del pais a partir de principios de siglo.

Durante este período, la economía y la sociedad paraguaya permanecieron dormidas, afectadas por el aislamiento del país, su inestabilidad política y las consecuencias de la guerra de 1865-1870, en defensa de su territorio contra Brasil, Argentina y Uruguay, que redujo su población a un cuarto de millón de personas, de las que solo 29.000 eran hombres.

Los intentos de integración de Paraguay en la economía mundial giraron en torno a la venta y concesión de extensas superficies públicas a compañías extranjeras, que explotaron los recursos forestales, desarrollaron la ganadería y establecieron colonias, y a una reducida inmigración de ultramar, unas 67.000 personas entre 1880 y 1950 . Dentro de esta inmigración figuran germanos y minorías que buscaron su aislamiento 


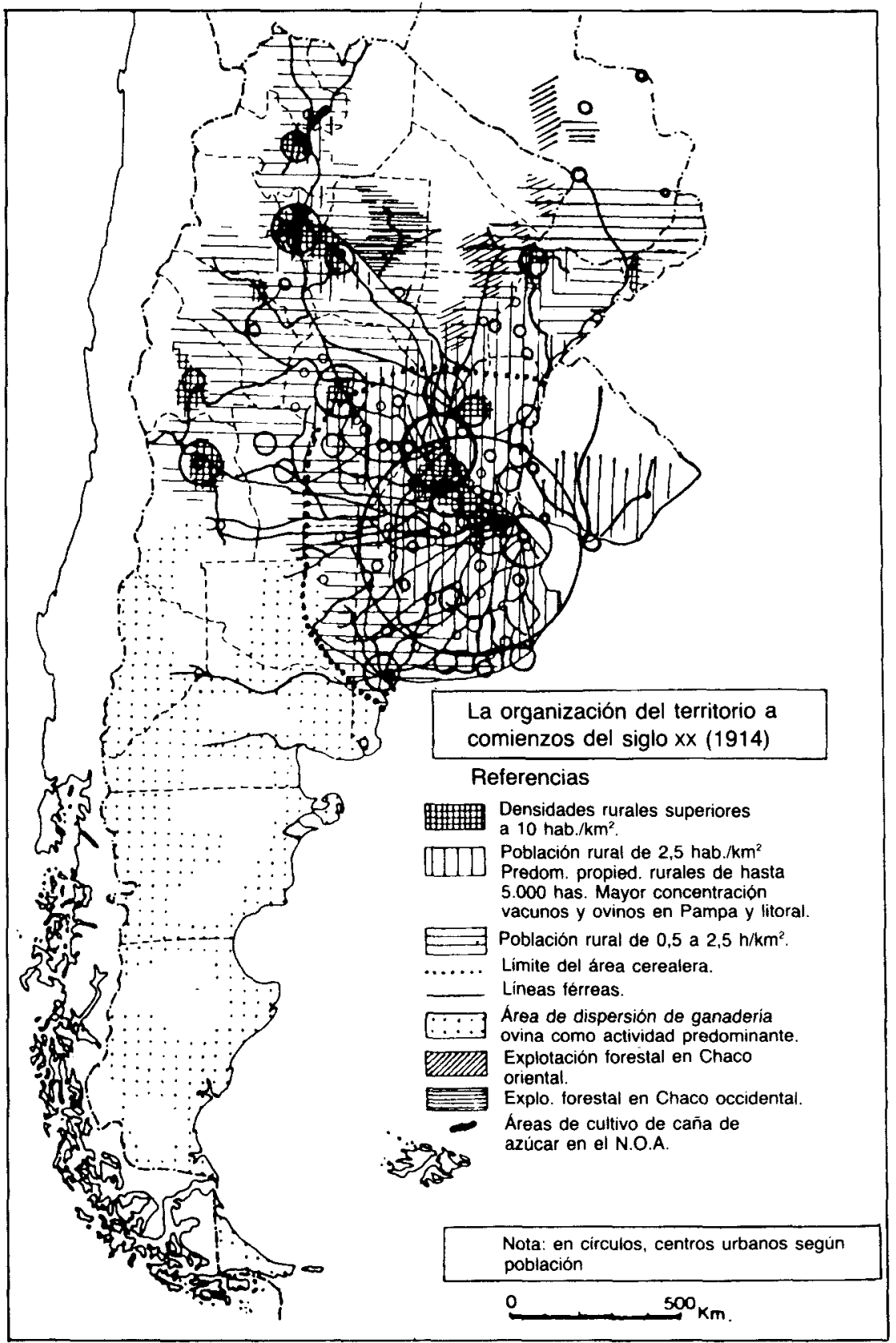

Fig. 2. Tomado y modificado de L. Bortagaray (1988) 
para desarrollar utopías políticas o religiosas, como los socialistas australianos cerca de Villarrica en 1893 y los Mennonitas en medio del Chaco en 1927.

Fuera de los bordes del Paraná y del ferrocarril, los pequeños campesinos, indígenas o inmigrantes, limitaron su actividad a una economía de subsistencia o de abastecimiento a las ciudades.

\section{EL MODELO DE CRECIMIENTO HACIA ADENTRO}

Primero la depresión de 1929 y luego la Segunda Guerra Mundial provocaron la quiebra del modelo de crecimiento agroexportador, con el consiguiente impacto sobre las actividades productivas, los flujos de población y el modelado de los paisajes sociales, al tiempo que crearon las condiciones para su sustitución por un modelo de crecimiento hacia adentro, basado en la industrialización, que llega hasta los años sesenta.

La depresión de los años treinta originó el hundimiento de los precios de los productos primarios y la contracción de los mercados ultramarinos; los paises industrializados levantaron barreras para proteger su agricultura y desarrollaron tecnologías capaces de reemplazar los insumos y disminuir el empleo por unidad de producto. Mientras, la abundancia de materias primas, el éxodo rural que creó abundante mano de obra de reserva en las ciudades, la necesidad de proporcionar bienes de consumo a una población en expansión y la restricción de importaciones de manufacturas a causa del estallido de la Segunda Guerra Mundial, estimularon el crecimiento de la industria doméstica a partir de los propios recursos.

En Argentina, la subida de Perón al poder en 1946, con el apoyo del proletariado urbano, favoreció aún más la industrialización. Con una politica de pleno empleo urbano y de aumento del consumo interno, en un proceso de estatización creciente, se emprendió un modelo de economía mixta planificada cuyo objetivo era la independencia de los grandes centros de decisión capitalista: Estados Unidos y Europa. Las industrias domésticas de bienes de consumo duraderos fueron impulsadas mediante el mantenimiento de precios bajos para los alimentos y altos niveles salariales, en tanto que las necesarias importaciones de bienes de capital, fuel y productos intermedios, fueron subsididas con la retención de gran parte de los beneficios de las exportaciones. 
Todo ello hizo que a principios de los años cincuenta la mayoria de los productos industriales consumidos en Argentina estuvieran fabricados en el propio pais; el valor de la producción industrial dentro del PNB superó al de las tradicionales actividades agricola-ganaderas y el número de obreros fue mayor que el de campesinos. Las industrias de bienes duraderos de consumo, que se desarrollaron durante los años treinta y cuarenta, fueron completadas durante la década de los cincuenta con la puesta en marcha de industrias pesadas y de fabricación de bienes de equipos, y con el inicio de una tímida entrada de inversiones extranjeras desde 1952. El comienzo de la explotación del mineral de hierro de Zaplá (Jujuy), en 1945, por la Dirección general de Fabricaciones Militares, y la extracción del carbón mineral del Río Turbio (Santa Cruz), a partir de 1947, permitieron el desarrollo de la industria siderúrgica. En 1958, entró en funcionamiento el importante complejo siderúrgico integral de General Savio, en San Nicolás de los Arroyos.

Durante estos años se consolidó el modelo de polarización espacial de la industria iniciado antes. La mayor parte de la industria, más del $80 \%$ de la producción y del $75 \%$ del empleo en 1960, se concentró en el frente fluvial de la Pampa ondulada, a lo largo de $360 \mathrm{~km}$, entre San Lorenzo (Santa Fe) y Ensenada (cerca de la ciudad de La Plata), pasando por el Gran Buenos Aires, debido a las ventajas de aglomeración: abundancia de mano de obra, magnitud del mercado urbano de consumo; a los beneficios que se derivaban de la primacia de este espacio como puerto de importación, a la disponibilidad de abundante energía, a la superioridad de los servicios de salud y educación, y a las ventajas derivadas de la proximidad a los aparatos de la administración y a los centros de decisión política en Buenos Aires.

En la zona de contacto de la llanura con las sierras Pampeanas, la ciudad de Córdoba se convirtió también en un importante foco industrial, gracias a la abundancia de energía hidroeléctrica, a la afluencia masiva de trabajadores y a la instalación de industrias mecánicas. Al mismo tiempo, el procesamiento de productos agrícolas locales dio lugar al nacimiento de complejos agroindustriales en Mendoza, Tucumán y Mesopotamia, en Misiones, Corrientes y Entre Ríos.

Sin embargo, aquella expansión industrial resultó poco eficaz; repartida la actividad industrial en miles de pequeños talleres, sin los beneficios de la economía de escala, con los inconvenientes de una red ferroviaria descapitalizada, de insuficientes inversiones en carreteras y de abastecimiento de energia por detrás de las necesidades, la producción industrial estuvo destinada casi exclusivamente al mercado interno, más 
del $95 \%$ de las exportaciones siguieron constituidas por tradicionales productos agrícolas ganaderos.

En Uruguay, el proceso de industrialización dirigido a la sustitución de importaciones, con un crecimiento por encima del $8 \%$, y un empleo industrial que pasó de los 111.000 obreros en 1948 a 208.000 en 1960, fue semejante al argentino. También aqui más de la mitad de los bienes manufacturados que se consumían, eran fabricados en el propio país en los años cincuenta. Los problemas de financiación y de estancamiento industrial han sido idénticos a los de Argentina, pero las dificultades para establecer industrias de base y de equipamiento han sido mucho mayores por el tamaño reducido del mercado, a pesar de disponer de energía hidroeléctrica suficiente y de una infraestructura de transportes más completa.

La guerra del Chaco (1933-35) permitió a Paraguay incorporarse nuevos territorios a expensas de Bolivia, pero a costa de un elevado número de vidas $y$ de ser un nuevo freno a la normalización política y económica. Paraguay siguió conservando su tradicional carácter rural; solo el auge de la industria de carne enlatada durante los años de la Segunda Guerra Mundial produjo cierta animación en su panorama económico.

Durante este periodo de crecimiento hacia adentro, la agricultura y la ganadería de los países del Plata se adaptaron a la nueva coyuntura económica a través del desarrollo de la mecanización del campo y a través de la introducción de formas más intensivas de usos del suelo, dirigidas a sustituir importaciones agrícolas con relación al proceso industrial y a abastecer mercados urbanos. No obstante, también se desarrollaron nuevos cultivos de exportación.

Por aquellos años, en la Pampa, aumentó espectacularmente la producción de oleaginosas, sobre todo de girasol, cacahuetes y soja, a expensas de los cereales que declinan; se intensificó la especialización ganadera y aumentaron las huertas y la ganadería lechera para aprovisionamiento de las ciudades.

El cultivo de la caña de azucar se extendió desde Tucumán a Jujuy y Salta, en condiciones climáticas más apropiadas; los viñedos de Cuyo y las superficies algodoneras del Chaco se ampliaron; la producción agrícola de Misiones se diversificó, y las frutas y vegetales templados adquirieron gran desarrollo en los regadíos de Mendoza, sobre todo alrededor de San Rafael, y en Patagonia, a lo largo del río Negro. El éxito de estos últimos cultivos se debió a sus posibilidades de industrialización (conser- 
vas, bebidas en zumo, fabricación de dulces y mermeladas) y a la exportación directa hacia mercados más lejanos.

Sin embargo, el descenso general de las ganancias del sector agrícola a lo largo de estos años y el escaso apoyo del peronismo al campo, provocaron la descapitalización de muchas explotaciones e hicieron descender las inversiones en el agro. La producción global agroganadera se retrajo, del $24,7 \%$ de la economía en $1940-44$ a sólo el $16,6 \%$ en 1950 54 , y la producción agrícola de la Pampa descendió al $84 \%$ de la que era en 1935-39.

Las actividades agricola-ganaderas de Uruguay evolucionaron de forma análoga a las de la Pampa. Con una política de bajos precios en el interior para la carne y dificultades para la exportación, que condujo al cierre de algunos frigoríficos, sólo la ganadería lechera experimentó un crecimiento. Los cultivos más tradicionales, como el trigo, el maíz y el lino, fueron reemplazados por el girasol para sustituir las importaciones de aceite de oliva y los cultivos de huerta fueron ampliamente desarrollados en las inmediaciones de Montevideo.

\section{NUEVA DEPENDENCIA Y CONSOLIDACIÓN DE LA POLARIZACIÓN ESPACIAL}

La incapacidad de los cambios económicos de los años cuarenta para generar una situación de crecimiento autosostenido a nivel mayor que el de subsistencia, deterioró el peronismo y propició el recurso a un nuevo modelo de crecimiento hacia afuera, pero ahora reforzando los lazos de dependencia respecto a los centros de decisión económica y política del planeta.

A la par que avanza la mundialización de la economía y progresa la revolución tecnológica, Argentina y Uruguay buscaron la solución a la escasez de divisas y a las deficiencias de sus sistemas productivos en políticas de estabilización y de liberalización económica que no sólo no modifican la organización y ordenación del territorio sino que vienen a consolidar los desajustes y desequilibrios anteriores.

A partir de los años sesenta, los paises del Plata hacen esfuerzos por reanudar las exportaciones agropecuarias y avanzan en la diversificación industrial; se facilitan las inversiones extranjeras directas e indirectas, favoreciendo la entrada de multinacionales que, a nivel general, con- 
tribuyen más a internacionalizar el consumo imitativo de los centros económicos que sus modos de producción; y se recurre a prestamos extranjeros cuyos intereses son representados por el Fondo Monetario Internacional. Sin embargo, todo ello, tras una etapa de desarrollo y expansión económica en los años sesenta, trajo consigo el aumento de la dependencia respecto a los grandes centros de decisión mundial, el incremento de las contradicciones internas $y$, en definitiva, el fracaso económico y la aparición de desequilibrios mayores en el seno de la sociedad, en un ambiente de crispación que culminó en los años setenta en el nacimiento de formas de guerrilla urbana y en el triunfo de dictaduras militares.

A finales de 1983, coincidiendo con el restablecimiento de la democracia en Argentina, las tasas de inflación superaron en este país el $1000 \%$ anual; su producción de bienes y servicios descendió al nivel de 1974 y el proceso de ajuste para pagar la deuda externa hizo retroceder la inversión como porcentaje del PIB desde un máximo histórico del $20 \%$ al $12 \%$. Hoy, el bienestar social ha caído fuertemente, nueve de los 30 millones de argentinos se hallan por debajo del umbral de máxima pobreza, el plan Austral de 1985 no consiguió frenar la inflación y el desarrollo económico y bienestar social prometidos por Carlos Menem durante su campaña electoral, a principios de 1989, están lejos.

El pago de la deuda externa, que asciende a más de 60.000 millones de dólares y el fracaso en la lucha contra la inflación son las principales dificultades de la economía de un país que, como algunos comentaristas señalan, cada vez parece ir más a la deriva. En nuestros días, las estrategias de crecimiento se basan en el ajuste económico, inspirándose en recomendaciones del Fondo Monetario Internacional y en una política económica ultraliberal basadas en las tesis del norteamericano Klein, premio Nobel de Economía, pero las consecuencias que se derivan de estas orientaciones: el incremento de las tarifas de los servicios públicos hasta un $500 \%$, la subida de precios de los bienes de uso corriente, la privatización de las empresas públicas y la reducción de los gastos del Estado, avivan el malestar y las tensiones sociales de unas clases trabajadoras que se sienten traicionadas por Carlos Menem, obligado a una política económica que supone un pacto con los principales agentes de poder del pais: la oligarquía agroexportadora, las multinacionales exportadoras de productos agrícolas, la banca internacional, los sectores liberales de las fuerzas armadas y la iglesia católica.

A mediados de 1990 se impuso la "dolarización" de la economía en una paridad de 10.000 por 1 que suponia la devaluación del austral. Con 
ello se pretende impulsar el ajuste económico, desalentar las importaciones, animar las exportaciones y favorecer las inversiones extranjeras que podrian comprar, practicamente a precio de saldo, empresas privadas y públicas. Asi, se pretende hacer compatible el pago de la deuda externa $y$ el necesario desarrollo.

El apoyo al sector agropecuario, favorecido por la subida de los precios mundiales de las materias primas en los años setenta, estimuló la recuperación agricola en regiones capaces de producir para la exportación, mientras que se producía el estancamiento de las regiones especializadas en cultivos para industrias nacionales, una vez alcanzado o sobrepasado el nivel modesto de demanda interior. La Pampa recuperó la estructura productiva tradicional y su posición privilegiada gracias a su capacidad para responder flexiblemente a las exigencias de la demanda, favorecida por las condiciones de clima, suelo, tamaño de las explotaciones, facilidades y bajo coste de acceso a los puertos, ahora mejorada la red de carreteras. Hoy, la Pampa concentra más del $70 \%$ del valor de la producción de cultivos de todo el país, el $85 \%$ de la producción ganadera y el $92 \%$ de la producción de cereales.

Fuera de la Pampa, ha aumentado la producción de frutales, sobre todo manzanas en Rio Negro; la superficie vitivinícola de San Juan y Mendoza permanece estabilizada; el algodón del Chaco retrocede, una vez que fueron retirados en 1959 los precios de garantía en beneficio de una mayor diversificación a partir del desarrollo de cultivos de sorgo y girasol, y se mantiene el predominio de la yerbamate, del tung y el té en Misiones, junto con el avance de la reforestación para la industria maderera.

En el sector ganadero las principales innovaciones han sido las relacionadas con la industria cárnica. Frente al sistema tradicional de pocos frigoríficos en los puertos, las nuevas formas de demanda, como la carne cortada sin hueso y empaquetada, y la mejora de los transportes, han facilitado la construcción de frigoríficos espacialmente dispersos y adaptados a las nuevas tecnologías. Hasta hace poco, el principal comprador de carne y trigo fue la desaparecida Unión Soviética, al contraerse el mercado británico y el de los países del sur de Europa debido a su integración en la CEE.

Desde mediados de los años cincuenta se avanzó en un proceso de desarrollo y de diversificación industrial comparable al de los paises más evolucionados. Los motores del cambio fueron: la prioridad dada a la expansión del petróleo y al gas natural para conseguir la independencia energética, con una red de oleoductos y gaseoductos de $9.000 \mathrm{~km}$; el desarrollo de industrias complementarias del refinado y petroquímica, con 
el aprovechamiento de nuevas cuencas petrolíferas en Salta y Magallanes y la atención puesta en las posibilidades de explotación de la plataforma submarina de las islas Malvinas; el interés por el aumento de la producción de electricidad, con los complejos hidroeléctricos del Limay, las realizaciones y proyectos del Uruguay y Paraná, y la puesta en funcionamiento en 1973 de la central nuclear de Atucha, la primera de Latinoamérica; la afluencia de inversiones extranjeras, concentradas en industrias química, petroquímica, vehículos y maquinaria; el crecimiento de la industria siderúrgica hasta una producción de 3,63 $\mathrm{m} / \mathrm{Tn}$ acero en 1987, alrededor del $85 \%$ de las necesidades; la estabilización de la industria de electrodomésticos; la promoción gubernamental de industrias de tecnología avanzada con gran capital de inversión y el programa de construcción y pavimentación de red de carreteras.

La participación de la industria en el PNB de Argentina pasó del $27,9 \%$ en 1950 a un máximo del $36,8 \%$ en $1975-77$, sin embargo la recesión económica mundial y la crisis económica y financiera de los ochenta derivada del endeudamiento con el exterior han provocado un proceso inverso de desindustrialización: en 1987, la participación de la industria en el PIB había descendido al $23 \%$. El fin de subvenciones a la exportación y la eliminación de tarifas, la pérdida de poder adquisitivo y la fragilidad del mercado nacional han provocado el cierre de numerosas fábricas y la salida de importantes empresas como la General Motors y la Chrysler.

A lo largo de estas últimas décadas todavía se ha potenciado más el modelo de localización concentrada de la industria en el frente fluvial de la Pampa y en Córdoba. Las $4 / 5$ partes de la industria petroquímica y las plantas siderúrgicas (San Nicolás, Constitución y Ensenada) se localizan en el eje Santa Fe-La Plata. Las industrias del motor se reparten entre el Gran Buenos Aires, Córdoba y Santa Fe.

Hoy, dentro de los intentos por conseguir la reactivación de la economía, destaca el empeño por aprovechar los variados y ricos recursos turísticos que ofrece la Argentina: desde el bosque húmedo de Misiones, con las famosas cataratas de Iguazu y ruinas de las misiones jesuíticas del siglo XVII, a los paisajes de alta montaña de los Andes húmedos de Bariloche, Andes áridos de Mendoza y Salta, balnearios del frente fluvial del Paraná y del Plata, y recursos de la costa marítima de la región bonarense y de Patagonia. No obstante, aunque los turistas procedentes del extranjero alcanzaron una cifra máxima de 1.608 .000 en 1984 , el turismo sigue siendo básicamente doméstico, debido a la distancia respecto a los grandes centros mundiales generadores de turismo y a que el viaje aéreo es relativamente caro. 


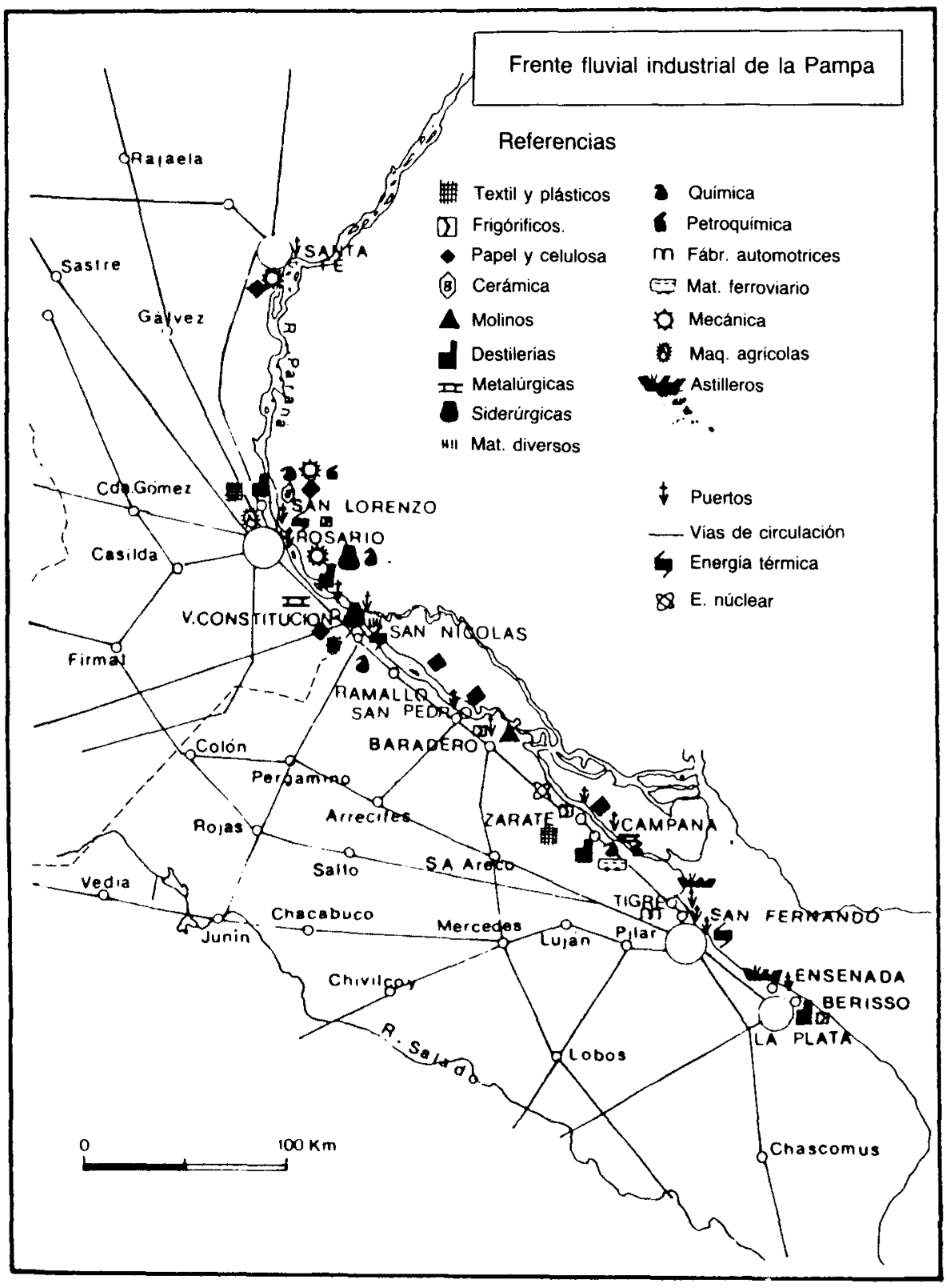

Fig. 3. Según F. A. Daus y A. del C. Yeannes (1988) 
En Uruguay, el nuevo modelo de crecimiento hacia el exterior, y con ello de mayor dependencia, se impuso a partir de la liberalización de su economía en 1973. Desde entonces se ha vuelto a potenciar el crecimiento económico sobre la base de la comercialización exterior de la producción agropecuaria, aprovechando el papel tradicional del país como uno de los principales provedores mundiales de carne y lana. A ello se han añadido los intentos por desarrollar la producción y exportación de los productos del mar, dentro de un ambicioso plan de desarrollo del sector iniciado en 1975, y la rápida expansión de la construcción, el comercio y los servicios.

La actividad industrial, sin modificar su modelo anterior de distribución espacial en torno a Montevideo, contribuía a la economía uruguaya con el $29 \%$ del PIB en 1988, gracias a la expansión de las industrias relacionadas con productos agropecuarios, al desarrollo por el Estado de las industrias del refinado de petróleo, de fabricación de cemento y alcohol; a una producción de energía hidroeléctrica muy abundante, por encima de las propias necesidades del país, y a una creciente penetración de capitales extranjeros. Sin embargo, desde 1981, la actividad industrial ha ido decayendo por su baja productividad, pérdida de competitividad, disminución de la demanda exterior y disminución del poder adquisitivo de la sociedad uruguaya. El recurso a la banca extranjera para financiar el desarrollo industrial en particular y económico en general en las últimas décadas ha hecho que Uruguay sea en la actualidad el país latinoamericano que presenta una deuda exterior per cápita más alta.

Al igual que en Argentina también ha habido un intento de potenciar el desarrollo turístico. El turismo es el más importante de los países del Plata, proporciona el $17 \%$ de las ganancias del comercio extranjero y sus ingresos se sitúan en tercer lugar en la tabla de beneficios por exportaciones, detrás de los que proceden de la lana y la carne. Los turistas proceden, sobre todo, de Argentina y Brasil, atraídos por las condiciones climáticas de la costa sur de Uruguay, por la infraestructura hotelera creada entre Montevideo y Punta del Este, por la proximidad respecto a Buenos Aires y por la calidad ambiental del centro histórico de Colonia del Sacramento, que funciona como área de segunda residencia para fines de semana y vacaciones de familias de la clase social alta bonarense.

En Paraguay, el modelo de crecimiento hacia afuera, con fuerte afluencia de capital extranjero, fue unido a la construcción conjunta con Brasil de la presa de Itaipu sobre el Paraná, el mayor complejo hidroeléctrico del mundo, en las inmediaciones de la ciudad fronteriza de Ciudad 
del Este; al desarrollo de cultivos de semilla de soja y algodón, orientados a la exportación; y a una cierta industrialización. En la década de los setenta, Paraguay, el país más pobre de la región, pasó a ser el de mayor incremento relativo económico, con tasas de crecimiento económico de más del $10 \%$ anual entre 1976 y 1980.

La explotación de los vastos recursos forestales, tan importante fuente de ingresos antes, sobre todo en lo referente al quebracho, ha ido decayendo durante las últimas décadas en beneficio de los cultivos agricolas, y lo mismo ha sucedido con la producción ganadera; en este caso, debido a las restricciones impuestas por sus tradicionales mercados de venta.

La industria, a pesar de su reducido tamaño y de participar solo con el $17 \%$ en el valor del PIB en 1988 y el $15 \%$ de la población activa en 1986, ha tenido un rápido desarrollo en los años setenta, favorecida por la abundancia de energía hidroeléctrica. Predominan las industrias de transformación de productos agrícolas con intervención de capital extranjero en las más importantes, mientras las de bienes de consumo están poco desarrolladas por el pequeño tamaño del país y la competencia del contrabando con los países vecinos. De cara a la exportación, las industrias principales son las textiles y de fabricación de cuero; por el contrario, las industrias empaquetadoras de carne han perdido la importancia que tenian antes por falta de competitividad y las restricciones impuestas en los mercados de la CEE.

Este proceso de industrialización se ha completado con la construcción de una planta siderúrgica al $\mathrm{N}$. de Asunción y el proyecto de construcción de otra en Walleni, con la puesta en funcionamiento de una gran planta estatal de fabricación de cemento para cubrir las necesidades derivadas de la construcción de grandes presas, y con el impulso dado por el gobierno a la fabricación de etanol a partir de la caña de azúcar desde 1980 , para su utilización como combustible teniendo en cuenta la inexistencia de yacimientos de hidrocarburos en el propio país.

Sin embargo, este crecimiento económico, como en el caso de los otros países del Plata no ha hecho sino aumentar la polarización espacial de la actividad económica y los desequilibrios regionales; aquí, al concentrarse los cambios y las innovaciones en las inmediaciones de la capital y en el Oriente, sobre todo en la zona fronteriza con Brasil y Argentina, alrededor de las ciudades de Hernandarias y de Ciudad del Este. Por el contrario la región del Chaco decae al tiempo que lo hacen los tradicionales aprovechamientos forestales y ganaderos. 


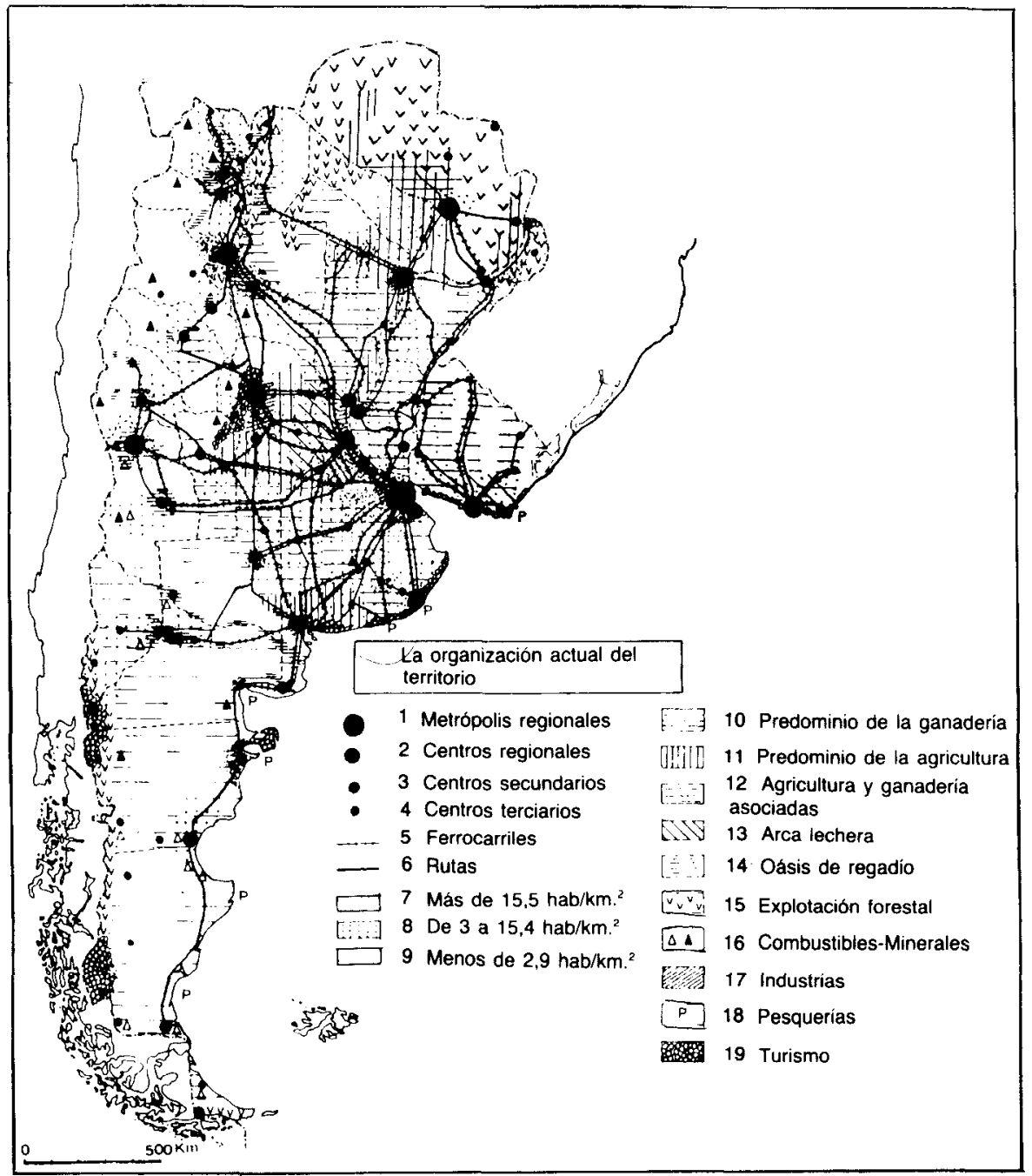

Fig. 4. Tomado y modificado de L. Bortagaray (1988) 
Desde 1981, el pago de una deuda exterior que en 1988 se elevaba a 1.180 millones de dólares, la inflación, el crecimiento anual de población, del $2,9 \%$ en 1989 frente al $1,3 \%$ de Argentina y el $0,8 \%$ de Uruguay, el desempleo y la crisis de sus gigantes vecinos, frenan el crecimiento económico y abren de nuevo una situación de incertidumbre para el futuro económico de Paraguay. No obstante, todavía se observan algunos síntomas esperanzadores en la evolución general del país, sobre todo en relación con el proceso de liberalización política y económica iniciado por el general Andrés Rodríguez, tras el derrocamiento del dictador Alfredo Stroessner en enero de 1989 y la celebración de las primeras elecciones libres, en mayo del mismo año. Todo ello ha permitido un crecimiento económico del $5,5 \%$ en 1989 , muy por encima de las tasas de crecimiento económico anual correspondientes a Argentina y Uruguay durante ese mismo año, $-0,6 \%$ en el primer caso y $0,5 \%$ en el segundo.

\section{CONCLUSIÓN: LA DIFICIL SALIDA DEL MODELO DE POLARIZACIÓN ESPACIAL Y DE DEPENDENCIA}

En una situación de crisis financiera que provoca el debilitamiento del Estado, con politicas erráticas incapaces de corregir los desequilibrios económicos y sociales, y que en Argentina y Uruguay suscitan el recelo y la desconfianza de unas clases medias que se proletarizan, hoy resulta difícil la movilización de recursos económicos y voluntades políticas para romper la excesiva polarización espacial metropolitana y conseguir la complementariedad entre los distintos espacios y actividades a partir del desarrollo de las metrópolis regionales y de los centros locales.

Como se señalaba al principio, la morfología excesivamente concentrada y centralizada del sistema urbano, de las actividades productivas, de la población, del poder político y financiero, de las redes y flujos de transporte, herencia todo ello de los modelos de economía dependiente dentro del esquema centro-periferia y del funcionamiento del capitalismo, son los principales obstáculos al desarrollo económico y a la incorporación plena al mundo evolucionado, al que, por otra parte, Argentina y Uruguay pertenecen desde hace muchos años en lo referente a numerosos indicadores sociales y poblacionales.

Los ejemplos de contradicciones y desequilibrios espaciales son numerosos en todo el conjunto regional de los países del Plata, pero son especialmente llamativos en Argentina por las dimensiones de su geografía; en todos ellos, contrastan las diferencias en calidad de vida y oportunidades para la población de unas y otras regiones, los contrastes entre 
espacios vacíos, áreas subutilizadas y áreas metropolitanas, afectadas por problemas de saturación, congestión y deterioro medioambiental que hacen poco rentable el funcionamiento de los servicios y disminuyen la eficacia del sistema económico.

Sin embargo, las exigencias de máxima obtención de beneficios por parte del gran capital y las consecuencias políticas y económicas de la grave situación financiera derivada de la deuda externa fuerzan a que se antepongan en todos estos países políticas de ajuste económico, siguiendo indicaciones del Banco Mundial y del Fondo Monetario Internacional, que se centran en el saneamiento de la economia a través de la reducción de la inflación, el fomento de las exportaciones y la disminución de las importaciones. Cualquier política de carácter territorial que suponga una reestructuración del aparato productivo y de las redes urbanas queda en un segundo plano cuando no postpuesta a un futuro indefinido, como en la práctica está sucediendo con muchos de los numerosos programas elaborados en Argentina para promover la ocupación de regiones escasamente pobladas, desarrollar las ciudades intermedias y estimular el desarrollo local con vistas a corregir los desequilibrios de redes urbanas incompletas. Por otra parte, esto mismo ayuda a explicar la dilación en el traslado de la capital federal desde Buenos Aires a un nuevo emplazamiento en Patagonia, entre las actuales ciudades de Viedma, Carmen de Patagones y el mar, a pesar de haber sido aprobado su traslado por Ley en 1987.

En definitiva, herencia histórica en las formas de ocupación del territorio en relación con formas antiguas de dependencia, intereses actuales del gran capital nacional e internacional como expresión de nuevas formas de dependencia, condicionantes derivados de la naturaleza del medio físico, problemas actuales relacionados con la deuda exterior, constituyen los elementos esenciales de un círculo vicioso del que resulta dificil salir y que es el principal responsable de la polarización espacial y de la dependencia del mundo del Plata. A todo ello se añade la crispación social que resulta de la dureza de la crisis actual, con manifestación en la hiperinflación (el cambio del dólar fijado en 650 australes a comienzo del mandato de Menem llegaba a 10.000 a mediados de 1990) y en una situación de hambre y miseria que cada vez afecta a sectores más amplios de la sociedad y crea un clima propicio para la revuelta y el motín popular, con el consiguiente peligro de desestabilización política para las recuperadas democracias en el ámbito del Plata. 


\section{BIBLIOGRAFIA}

Argentina. EIU Country Report n. ${ }^{\circ}$ 4, 1989.

BortagaraY, L. 1988: "Las etapas de ocupación del territorio argentino", en La Argentina, J. A. Roccatagliata (coord.). Buenos Aires. Planeta, págs. 147-168.

BouRde, G. 1974: Urbanisation et inmigration en Amérique Latine. Paris, Ed. Aubier Montaigne.

Centro nacional de Estudiantes de Ciencias Económicas y AdminisTRACIÓN 1976: «Plan nacional de desarrollo económico y social 19651974", Uruguay, 2 vols., Montevideo.

CEPAL. (ONU), 1985: Anuario Estadístico de América Latina y el Caribe.

Clichevsky, N. 1991: "Sobre la planificación urbana posible en los ochenta. El caso del área metropolitana de Buenos Aires", en Ciudad y Territorio, n. ${ }^{\text {ss }} 86-87$, págs. 513-524.

García Alvarado, J. M. 1989: Uruguay. Madrid, Biblioteca Iberoamericana. Ed. Anaya.

Garcia Alvarado, J. M. y Gutiérrez Puebla, J. 1989: Paraguay. Madrid. Biblioteca Iberoamericana, Ed. Anaya.

INForme sobre el Desarrollo Mundial, 1989: Washington, D. C., Banco Mundial. 
VI Jornadas Cuyanas de Geografía. Congreso Nacional e InternacioNAL. 1989: Resúmenes. Mendoza. Instituto de Geografía, Facultad de Filosofía y Letras. Universidad Nacional de Cuyo.

KAY, C. 1989: Latin American Theories of Development and Underdevelopment. London, Routledge.

LAMBeRT, D. C. 1984: 19 Amériques Latines. Déclins et décollages. Paris, Económica.

MATE, V. 1988: "Nuevo modelo de acumulación hacia afuera en Argentina», en Crisis Económica Mundial y Tercer Mundo. Madrid, Ed. IEPALA, págs. 5 a 196.

Rocatagliata, J. A. 1984: La organización del territorio argentino. Mendoza, Universidad Nacional de Cuyo, 2 vols.

RocatagliAtA, J. A. 1988: "Los transportes y las comunicaciones", en La Argentina, Buenos Aires, J. A. Roccatagliata (coord.), Planeta.

Rock, D. 1988: Argentina 1516-1987. Desde la colonización española hasta Raul Alfonsín. Madrid, Alianza Editorial.

Uruguay/Paraguay, EIU, Country Report, n. ${ }^{\circ} 1,1989$.

Zamorano Díaz, M. 1988: Argentina. Madrid, Biblioteca Iberoamericana. Ed. Anaya.

Zarate, A. 1990: "El modelo urbano de los Países del Río de la Plata", en Espacio, Tiempo y Forma, Serie VI, Geografía, t. 3, págs. 195214. 